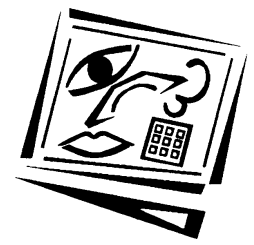

\title{
Effects of presentation mode on mobile language learning: A performance efficiency perspective
}

\author{
I-Jung Chen \\ Takming University of Science and Technology \\ Chi-Cheng Chang \\ National Taiwan Normal University \\ Jung-Chuan Yen \\ Takming University of Science and Technology
}

\begin{abstract}
This study investigated the effects of simultaneous written text on the comprehension of spoken English as a foreign language, when the text is presented with the aid of a personal digital assistant (PDA) as a learning tool. Eighty-seven university students majoring in applied foreign languages were randomly assigned to either listening with auditory materials only, or listening with identical and concurrent written text. Performance efficiency was used to provide a better indicator of the quality of learning. The results revealed that for learners with lower English levels, the presence of concurrent written text elicited higher performance efficiency in the immediate recall task of the English listening comprehension. However, the beneficial effect of the written text did not extend to the subsequent auditory-only passage. The study suggested that when using mobile devices as training tools, the provision of written text facilitates the acquisition of information but not the schema construction of the English listening comprehension skill.
\end{abstract}

\section{Introduction}

\section{Mobile learning}

With the rapid advancement of wireless technology, mobile learning (m-learning) has emerged as an innovative learning concept which takes advantage of the mobility of learning devices such as cell phones, personal digital assistants (PDAs), tablet PCs, and MP3 players. This development is especially evident with the ever-increasing number of e-book reading devices available; these devices enable information and knowledge acquisition at any moment, even when users are on the move. The convenience and immediacy of m-learning warrant further investigation on instructions carried out with the aid of mobile devices (Nash, 2007).

"M-learning" refers to the use of mobile technologies for pedagogical purposes. Geddes (2004, p.1) defined mobile learning as "the acquisition of any knowledge and skill through use of mobile technology, anywhere, anytime which results in an alteration in behavior." Mobile devices are advantageous over desktop PCs because of their small size, light weight, affordable price, and short boot-up time. KukulskaHulme (2009) highlighted the unique affordances of these devices: spontaneous, informal, contextual, portable, ubiquitous, pervasive, and personal. Mobile 
technologies can thus support learning that is more situated, experiential, and contextualized within specific domains (Kukulska-Hulme \& Traxler, 2005). Further advantages include immediate sharing of ideas and information as well as the motivational effect from the novelty of the devices (Pettit \& Kukulska-Hulme, 2007). In short, mobile devices allow learners to engage in educational activities while interacting within real contexts and gain first-hand experience. To add to the benefit of mobility, there is also a wealth of L2 learning resources freely available to users on the Internet, such as podcasts, which provide access to authentic inputs for language learning. Learners download the topics they enjoy and engage in learning anywhere, anytime.

The promising capabilities of portable devices in the context of learning have given rise to abundant applications and instructional designs for m-learning. Even on school campuses, the traditional classroom can be transformed into a digital laboratory with a mobile device in hand. Considering the current global situation characterised by budget constraints, mobile devices not only come in handy but are also cost effective in functioning as a digital laboratory. Several studies that employed mobile devices in the classroom reported that such devices enhanced student engagement. For example, Davis (2003) implied that all the students in a classroom could respond to the teacher's questions instantly and anonymously through mobile devices, which enabled the instructor to assess how all students were doing at any time during a lesson. Further, because of the anonymity involved, students were more willing to take risks in exploring answers.

However, learning does not take place simply with the use of tools. In order to support the learner's knowledge development, it is important to re-examine instructional designs to maximise the advantages of these innovative learning tools. Chen, Hsieh and Kinshuk (2008) urged that incorporating related learning theories and instructional strategies into innovative learning forms significantly improved the outcomes of learning. Cheung and Hew (2009) made a similar suggestion that researchers invoke appropriate theoretical foundations when applying the latest technology to inform new studies. In response to the calls by Chen et al. and Cheung and Hew, the present study aims to explore the effectiveness of different modes of content presentation in mobile devices for foreign language learning, within the framework of cognitive load theory. This theory has been employed successfully as a theoretical base in many subjects that use multimedia-aided content presentation for learning purposes.

\section{Cognitive load theory}

Cognitive load theory (CLT) addresses the limited capacity of the human working memory, which is able to hold and process only a few items of information at a time, and long-term memory, which has unlimited capacity (Sweller, 2005). Most human cognitive action is driven by the contents of long-term memory (Chase \& Simon, 1973). Knowledge elements are assumed to be stored in long-term memory in schematic forms. A schema is a cognitive construct that organises information for storage in longterm memory. When brought into working memory from long-term memory, a schema allows us to treat multiple elements of information as a single element categorised according to the way in which it will be used (Sweller, 2005). The ultimate goal of learning, therefore, is to build schemas in long-term memory, referred as schema construction in the lsections below. Cognitive load refers to the total amount of mental 
activity imposed on the working memory at an instant in time (Cooper, 1998). When the load exceeds the capacity of working memory, learning is impeded. Therefore, well-designed instruction seeks to increase the capacity and decrease the cognitive load of working memory as much as possible. CLT has been used to generate many instructional procedures (Sweller, 2003), including the modality effect and the redundancy effect. These effects will be discussed below.

\section{Modality effect vs. redundancy effect}

With the proliferation of multimedia technologies, instructional materials are able to incorporate varied forms of multimedia to simultaneously provide the learners with rich sensory stimuli. According to the "Working Memory Model," proposed by Baddeley (2000) when information is presented to two sensory channels - visual and audio - instead of one, both modalities are activated and the performance of the working memory is enhanced because more information can be processed. This is called the "modality effect" in CLT (Sweller, 2005). The modality effect has been tested extensively in different subjects using instructions given through multimedia and by incorporating various modes of presentation (Kalyuga, Chandler \& Sweller, 1999; Leahy, Chandler \& Sweller, 2003; Mayer \& Moreno, 1998; Moreno \& Mayer, 2002; Mousavi, Low \& Sweller, 1995; Sweller, 1993). The results have indicated that the dual sensory mode - using both visual and auditory channels simultaneously - had positive effects on learning only when individual information was unintelligible in isolation. In other words, the modality effect is obtained when one channel is used to compensate for the other.

On the other hand, when multiple sources of information are presented, where one source is sufficient to allow understanding and learning while the other sources merely reiterate the information of the first source in a different form, the superfluous materials force a severely constrained working memory to process unnecessary and redundant information, thus leading to ineffective learning. This is referred to as the "redundancy effect" (Sweller, 2005). Evidence on the redundancy effect have been provided in a number of studies using visual and audio instructional presentation, namely, written versus spoken text or diagram versus spoken text (Jamet \& Bohec, 2007; Kalyuga, et al., 1999; Kalyuga, Chandler \& Sweller, 2000; Mayer, Heiser \& Lonn, 2001). The redundancy effect, however, depends on the learner's expertise level, which implies that information that is redundant for skilled learners may be essential for novices. This is termed as the "Expertise Reversal Effect" (Sweller, 2005).

\section{Listening comprehension in second or foreign languages}

Learning a foreign language (L2) is inherently different from learning other subjects. While engaging in L2 learning, students have to manage both content knowledge and linguistic knowledge simultaneously; this often imposes a heavy cognitive load on working memory. This is especially true with listening comprehension for L2 learning. Listening in almost any setting is the most frequently used language skill, and yet, it is often perceived to be particularly difficult and causes frustration and anxiety among L2 learners because of its transient nature (Goh, 2000; Kao, 2006). In other words, the relaying of the message is an ongoing process, and usually, the listener has neither control over the speech rate nor an opportunity to review the message. As described by Osada (2004), to capture the information in spoken language, listeners must (1) comprehend the text as they listen to it, (2) retain information in their working 
memory, (3) integrate it with what follows, and (4) continually adjust their understanding of what they hear in the light of prior knowledge and incoming information.

Because of the multiple tasks that a learner has to perform simultaneously when processing a spoken message in L2, it is assumed that, due to the modality effect, the written text assists the comprehension of the message by activating both audio and visual modalities and increasing the processing resources of the working memory. However, Diao, Chandler and Sweller's (2007) study on the effects of written text on comprehension of L2 spoken messages and cognitive load, which they conducted with PCs, suggested that additional written text facilitated the immediate facts recall of L2 listening comprehension, but provided only limited benefit for schema construction in the long-term memory. The basis for the argument was that the improved performance of the participants supplied with identical text messages could be attributed to their reading rather than their listening to the materials.

The present study intended to verify whether the research results of Diao et al. can be extended to situations where mobile devices are used as a learning tool. According to the CLT, the appropriate mode of content delivery designed for specific tools and instructional objectives minimises memory loads and maximises learning outcomes. However, early research on mobile language learning focused mostly on system construction (Chen \& Chung, 2008; Chinnery, 2006; Cooney \& Keogh, 2007; Hung \& Young, 2007; Saran, Cagiltay \& Seferoglu, 2008; Stockwell, 2007). Materials and instructional strategies aimed for mobile use have not gained much attention in the literature. In addition, mobile learning often occurs in a constantly changing environment, which is very different from learning with desktop computers. Mobility may provoke a high cognitive load because environmental variations or context differences often impose distractions or even threats to learners (Nash, 2007). Finally, the small screens of mobile devices has often been reported as one of the major disadvantages of mobile learning, because it may require extra effort in reading the materials (Ally, 2004; Cheung \& Hew, 2009; Hsi, 2003; Nash, 2007; Paas \& Van Merriënboer, 1994; Pettit \& Kukulska-Hulme, 2007). There is, hence, an urgent need to understand how learners perceive and process an external stimulus when using mobile devices for learning, so that the findings can help practitioners to make informed decisions in their applications of mobile learning.

In order to produce a better indicator about the quality of learning, the "efficiency measure" (Paas \& Van Merriënboer, 1993) was employed to examine the effects of the modality. Performance efficiency was calculated on the basis of the mental effort expended when performing a task. The formula used was $E=P-M / 2^{0.5}$, where $E$ stands for efficiency, $P$ for performance, and $M$ for mental effort. To calculate the efficiency measure, the cognitive load rating on the task was combined with the performance measure, rather than attending to the two measurements separately. The efficiency measure can provide information on the relative involvement of students in the instructional condition. In this study, the authors hypothesised that a concurrent written and spoken mode of presentation would facilitate L2 listening comprehension by increasing the cognitive resources as both the audio and visual senses were used. Considering the expertise reversal effect, this study further hypothesised that the modality effect would be reversed with learners who have a high expertise level, which was defined as students' L2 proficiency in listening comprehension for the present study. 
In the experiment conducted as part of this study, two formats for presenting contents were compared, namely, dual mode presentation and single mode presentation. In the dual mode, the listeners were provided with written and spoken messages simultaneously; in the single mode, they were provided with spoken messages only. The purpose of the instruction was to help learners construct schemas in long-term memory (Van Merriënboer \& Sweller, 2005). The experiment comprised two subsequent sessions: an immediate recall task and a skill transfer task to test the learners' working memory and long-term memory respectively. Investigating the instructional effectiveness of the mode of presenting contents with the mobile devices from the perspective of cognitive load theory will enhance the advancement of instructional design for m-learning.

\section{Method}

\section{Participants}

A total of 87 students (17 males and 70 females aged 18-22 years) majoring in Applied Foreign Languages at a technology university in northern Taiwan participated in the study. All of them shared the same first language, Mandarin; none of them had studied abroad before. They had previously undergone six years of formal English instruction in general high school and entered the university based on scores received in the Joint College Entrance Examination. Participants' similar educational experience as well as linguistic and cultural homogeneity was hence assumed.

\section{Materials and procedure}

This was a pilot study for some later work on mobile L2 listening comprehension training in the zoo (Chen \& Chang, 2011). The pilot experiment, conducted in June 2009 , included three phases. The first phase was to determine the expertise levels of the participants and was carried out one week before the instructional activity. To obtain participants' proficiency levels in English listening comprehension as the learner expertise level (EL), the researchers employed a listening comprehension test of intermediate-level General English Proficiency Test (GEPT), which is a public test of English language proficiency, designed and administered by the Language Training \& Testing Center (LTTC) and supervised by the Taiwanese Ministry of Education. The LTTC GEPT has five levels (elementary, intermediate, high-intermediate, advanced, and superior) and includes listening, reading, writing, and speaking components. Since the present study focused on the learning of listening comprehension, only the listening comprehension section was used for the test. The intermediate level was adopted because the basic requirement for graduation from the Department of Applied Foreign Languages is to pass the intermediate level of the GEPT. According to the descending order of their test scores, the students were divided into three categories high EL, medium EL, and low EL, each EL comprising 29 students.

PDAs provided by our laboratory were adopted as the mobile learning tools. Since there were only a limited number of PDAs available, the experiment was conducted twice, with 44 participants in one round and 43 in the other, using exactly the same procedure. Each PDA had one of the two presentation modes installed. The participants in each EL (high, medium and low) were randomly assigned to either the single mode group (spoken message only) or the dual mode group (spoken message plus identical written text). Figure 1 shows examples of PDA screen pictures. 

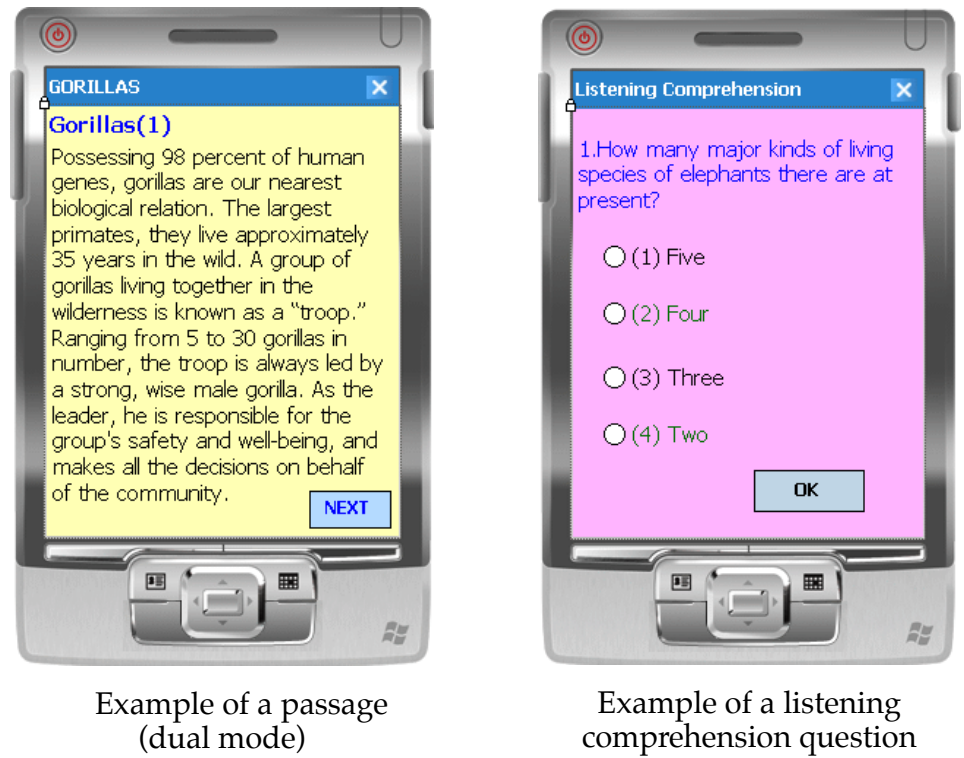

Figure 1: Screen pictures of the PDA

The instructional material for the second phase (a week after the pre-test) contained three passages talking about animals - namely, elephants, gorillas and lions. The contents were adapted from the website of the San Diego Zoo. The length of the passages ranged from 180 to 220 words. Each passage had five multiple-choice questions to test the performance of the participants in the immediate factual recall task (See Appendix 1). This phase was to probe the effect of the different presentation modes on the immediate recall task.

The final phase, conducted one hour after the completion of the second phase, was to investigate the effect of different presentation modes on the skill transfer ability. The skill transfer test was a 220-word article on the origin and rules for the game of tennis. It was composed including keywords and expressions from the passages on animals in the previous phase (See Appendix 2). This article was an extended learning from the second phase aimed at investigating the impacts of these two modes on the skill of L2 listening comprehension transferred into schema. This passage was provided to all participants through a single mode - spoken message only - because the ultimate goal of the task was to help students develop their listening comprehension skills. The performance of the participants in the listening comprehension of this passage indicated the degree to which the schema had been constructed.

All passages and questions for the study were reviewed and recorded by two native English speakers and pilot-tested with 25 students other than the participants, to ensure that none of the questions confused the listeners because of unclear statements.

After listening to each passage (in both phases), all participants were required to rate their perceptions of the difficulty level of the task on a 7-point scale, ranging from $1=$ "extremely low" to 7 = "extremely high." A higher score indicated a higher mental effort. Many researchers have successfully used the perceived difficulty of tasks to measure learners' mental effort as the cognitive load imposed in the learning process 
(Borg, Bratfisch \& Dornic, 1971; Chung, 2008; Kalyuga, Chandler \& Sweller, 1998; Yeung, Jin \& Sweller, 1997). According to these studies, a subjective rating is reliable and sensitive for measuring memory load (DeLeeuw \& Mayer, 2008; Paas, Van Merriënboer \& Adam, 1994).

\section{Results}

\section{Performance and cognitive load}

First, an item analysis was conducted to examine for any marked differences in each listening comprehension question between the high scores and low scores (the top $27 \%$ and bottom $27 \%$ of the test scores, respectively). Results showed that three test items were not significantly different between the two groups (Table 1). Therefore, these three items of the recall test $(\mathrm{Q} 2, \mathrm{Q} 12$, and Q13) were deleted.

Table 1: Item analysis of the test

\begin{tabular}{|c|c|c|c|}
\hline \multirow{2}{*}{ Item } & \multicolumn{2}{c|}{ Item analysis } \\
\cline { 3 - 4 } $\begin{array}{c}\text { Recall } \\
\text { test }\end{array}$ & Q1 & t (Sig) & Correlation (Sig) \\
\cline { 2 - 4 } & Q2 & $1.620(0.11)$ & $0.163(0.13)$ \\
\cline { 2 - 4 } & Q3 & $4.587(0.00)$ & $0.439(0.00)$ \\
\cline { 2 - 4 } & Q4 & $4.074(0.00)$ & $0.436(0.00)$ \\
\cline { 2 - 4 } & Q5 & $2.345(0.02)$ & $0.233(.030)$ \\
\cline { 2 - 4 } & Q6 & $6.273(0.00)$ & $0.496(0.00)$ \\
\cline { 2 - 4 } & Q7 & $4.526(0.00)$ & $0.457(0.00)$ \\
\cline { 2 - 4 } & Q8 & $4.065(0.00)$ & $0.446(0.00)$ \\
\cline { 2 - 4 } & Q9 & $3.599(0.00)$ & $0.377(0.00)$ \\
\cline { 2 - 4 } & Q10 & $4.158(0.00)$ & $0.370(0.00)$ \\
\cline { 2 - 4 } & Q11 & $3.463(0.00)$ & $0.406(0.00)$ \\
\cline { 2 - 4 } & Q12 & $1.047(0.30)$ & $0.135(0.21)$ \\
\cline { 2 - 4 } & Q13 & $1.467(0.15)$ & $0.203(0.06)$ \\
\cline { 2 - 4 } & Q14 & $2.025(0.05)$ & $0.264(0.01)$ \\
\cline { 2 - 4 } & Q15 & $3.642(0.00)$ & $0.413(0.00)$ \\
\hline \multirow{7}{*}{$\begin{array}{c}\text { Transfer } \\
\text { test }\end{array}$} & Q1 & $5.675(0.00)$ & $0.609(0.00)$ \\
\cline { 2 - 4 } & Q2 & $5.342(0.00)$ & $0.522(0.00)$ \\
\cline { 2 - 4 } & Q3 & $4.660(0.00)$ & $0.474(0.00)$ \\
\cline { 2 - 4 } & Q4 & $12.304(0.00)$ & $0.669(0.00)$ \\
\cline { 2 - 4 } & Q5 & $4.660(0.00)$ & $0.545(0.00)$ \\
\hline
\end{tabular}

For the preliminary analysis, the results of one-way ANOVA revealed three ELs were significantly different in their listening comprehension ability, $F(2,84)=203.053$, $M S E=3.870, p=0.000, \eta^{2}=0.828$. A series of 2 (presentation mode) $\times 3(E L)$ analysis of variance with between-subject factors was conducted on the scores of the recall test and transfer test, as well as the corresponding perceived cognitive load (CL) ratings. A 0.05 significance level was used throughout the study. The means and standard deviations are given in Tables 2 and 3. The results of two-way ANOVA showed a main effect of the presentation mode on the recall test scores, $F(1,81)=14.975, M S E=4.093$, $p=0.000, \eta^{2}=0.156$, with the dual-mode group outperforming the single-mode group, and a secondary effect on the corresponding perceived CL ratings, $F(1,81)=4.688$, $\left.M S E=5.042, p=0.033, \eta^{2}=0.055\right)$, with higher perceived CL ratings reported by the single-mode group than by the dual-mode group. However, there was no main effect of the presentation mode on either the transfer test scores, $F(1,81)=0.330$, 
$M S E=1.471, p=0.568$, or the corresponding perceived CL ratings, $F(1,81)=0.524$, $M S E=0.859, p=0.471$.

A significant main effect of the EL was observed on the recall test scores, $F(2,81)=8.940, M S E=4.093, p=0.000, \eta^{2}=0.181$, and the transfer test scores, $F(2,81)=9.736, M S E=1.471, p=0.000, \eta^{2}=0.194$. Post hoc comparisons (Scheffe) of different groups for both the recall test and transfer test revealed that the high EL group scored better than the medium and low EL groups; however, no main effect of the EL was observed on the perceived CL of the recall test, $F(2,81)=1.793$, $M S E=5.042, p=0.173)$. A significant difference in the perceived CL was found for the transfer test, $F(2,81)=3.866, M S E=0.859, p=0.025, \eta^{2}=0.087$. The post hoc comparisons indicated that both the medium and low EL groups reported higher perceived CL of the transfer test than the high EL group did.

No interaction effects were found on the recall test scores, $F(2,81)=0.958, M S E=4.093$, $p=0.388$; transfer test scores, $F(2,81)=1.293, M S E=1.471, p=0.280$; perceived CL of the recall test, $F(2,81)=0.659, M S E=5.042, p=0.520$; or the perceived $C L$ of the transfer test, $F(2,81)=0.424, M S E=0.859, p=0.656$ In other words, the presentation mode did not interact with the EL to bring about differences on the dependent variables.

Table 2: Overview of the results

\begin{tabular}{|l|c|c|c|c|c|c|c|c|}
\hline & \multicolumn{4}{|c|}{ Single mode $(n=45)$} & \multicolumn{4}{c|}{ Dual mode $(n=42)$} \\
\cline { 2 - 10 } & $\begin{array}{c}\text { Recall test } \\
\text { score }\end{array}$ & $\begin{array}{c}\text { Recall } \\
\text { CL }\end{array}$ & $\begin{array}{c}\text { Transfer } \\
\text { test score }\end{array}$ & $\begin{array}{c}\text { Transfer } \\
\text { CL }\end{array}$ & $\begin{array}{c}\text { Recall test } \\
\text { score }\end{array}$ & $\begin{array}{c}\text { Recall } \\
\text { CL }\end{array}$ & $\begin{array}{c}\text { Transfer } \\
\text { test score }\end{array}$ & $\begin{array}{c}\text { Transfer } \\
\text { CL }\end{array}$ \\
\hline Means & 5.89 & 12.56 & 2.89 & 4.11 & 7.40 & 11.60 & 2.93 & 4.31 \\
\hline SD & 2.24 & 2.32 & 1.48 & 0.94 & 2.19 & 2.20 & 1.18 & 0.98 \\
\hline
\end{tabular}

Note: $\mathrm{CL}=\mathrm{Cognitive} \mathrm{load}$. The potential range of scores was $0-12$ for the recall test, $0-5$ for the transfer test, 3-21 for the recall CL (where "recall CL" is the perceived CL for the recall test), and 1-7 for the transfer CL (where "transfer CL" is the perceived CL for the transfer test).

Table 3: Means and standard deviations of the test scores and the cognitive load

\begin{tabular}{|l|c|c|c|c|c|c|c|}
\hline \multicolumn{2}{|c|}{} & \multicolumn{2}{|c|}{ Single mode, expertise level } & \multicolumn{2}{c|}{ Dual mode, expertise level } \\
\cline { 3 - 9 } & & $\begin{array}{c}\text { High } \\
n=17\end{array}$ & $\begin{array}{c}\text { Medium } \\
n=14\end{array}$ & $\begin{array}{c}\text { Low } \\
n=14\end{array}$ & $\begin{array}{c}\text { High } \\
n=12\end{array}$ & $\begin{array}{c}\text { Medium } \\
n=15\end{array}$ & $\begin{array}{c}\text { Low } \\
n=15\end{array}$ \\
\hline \multirow{2}{*}{ Recall test } & $\mathrm{M}$ & 7.35 & 5.57 & 4.43 & 8.42 & 7.07 & 6.93 \\
& SD & 2.21 & 1.65 & 1.74 & 2.20 & 2.40 & 1.79 \\
\hline Transfer test & $\mathrm{M}$ & 3.82 & 2.64 & 2.00 & 3.58 & 2.60 & 2.73 \\
\cline { 2 - 9 } & SD & 1.02 & 1.39 & 1.47 & 1.08 & 1.18 & 1.10 \\
\hline Recall CL & $\mathrm{M}$ & 11.65 & 13.36 & 12.86 & 11.25 & 11.60 & 11.87 \\
\cline { 2 - 9 } & SD & 2.78 & 2.13 & 1.51 & 1.82 & 2.32 & 2.45 \\
\hline Transfer CL & $\mathrm{M}$ & 3.65 & 4.43 & 4.36 & 4.00 & 4.33 & 4.53 \\
\cline { 2 - 9 } & SD & 1.00 & 0.94 & 0.63 & 0.74 & 1.18 & 0.92 \\
\hline
\end{tabular}

Note: $\mathrm{CL}=$ Cognitive load. The potential range of scores was $0-15$ for the recall test, $0-5$ for the transfer test, 3-21 for the recall CL (where "recall CL" is the perceived CL for the recall test), and 1-7 for the transfer CL (where "transfer CL" is the perceived CL for the transfer test).

\section{Performance efficiency}

As mentioned in the introduction, performance efficiency can provide information on the relative involvement of students in the instructional condition. A low mental effort combined with a high performance score will yield high efficiency, while a high mental 
effort combined with a low performance score will result in a low efficiency score. In the present study, performance was measured as the scores obtained in the listening comprehension task and the mental effort was the degree of perceived difficulty of the task (Yeung, Jin \& Sweller, 1997). The performance measures and mental effort of each participant were first standardised (transformed into z-scores using the grand mean across conditions) to permit comparisons. An equal performance and mental effort $\mathrm{z}$ score yielded a performance efficiency of 0 - a neutral score. If $\mathrm{P}>\mathrm{M}$, the content presentation is more efficient, indicated by a positive value, where as if $P<M$, the content presentation is less efficient, indicated by a negative value.

To compare the impacts of the content presentation mode on the performance efficiency, a 2 (presentation mode) $\times 3$ (EL) ANOVA with between-subject factors was conducted on the recall task and transfer task, respectively. Tables 4 and 5 show the means and standard deviations of the performance efficiency of the two tasks. The findings showed a main effect of the presentation mode on the performance efficiency of the recall task, $F(1,81)=13.979, M S E=1.072, p=0.000, \eta^{2}=0.147$. The dual-mode group had a positive efficiency value, whereas the single-mode group had a negative efficiency value. In other words, the dual mode had higher performance efficiency than the single mode on the immediate factual recall task. Meanwhile, the main effect of the presentation mode was not significant for the efficiency of the transfer task, $F(1,81)=.015, M S E=1.067, p=0.901$. However, the mean difference implied that the single mode group had a slightly higher mean value than the dual mode group (Table 4). To give a better understanding of the differences between the ELs, Table 5 shows that the higher mean was a result of better performance efficiency by the high EL group with the single mode.

Table 4: Overview of the performance efficiency results

\begin{tabular}{|l|c|c|c|c|c|}
\hline \multicolumn{2}{|c|}{} & \multicolumn{2}{c|}{ Single mode $(n=45)$} & \multicolumn{2}{c|}{ Dual mode $(n=42)$} \\
\cline { 3 - 6 } \multicolumn{2}{|c|}{ Performance efficiency } & Recall task & Transfer task & Recall task & Transfer task \\
\cline { 2 - 6 } & SD & -0.3653 & 0.0621 & 0.3902 & -0.0639 \\
\hline
\end{tabular}

Table 5: Means and SDs of the performance efficiency of the recall and transfer tasks

\begin{tabular}{|l|c|c|c|c|c|c|c|}
\hline \multicolumn{2}{|c|}{} & \multicolumn{3}{c|}{ Single mode, expertise level } & \multicolumn{2}{c|}{ Dual mode, expertise level } \\
\cline { 3 - 8 } & & High & Medium & Low & High & Medium & Low \\
& & & $n=17$ & $n=14$ & $n=12$ & $n=15$ & $n=15$ \\
\hline Recall efficiency & $\mathrm{M}$ & 0.3585 & -0.7081 & -0.9014 & 0.8035 & 0.2860 & 0.1636 \\
\cline { 2 - 8 } & SD & 1.3364 & 0.7796 & 0.5176 & 0.9549 & 1.0883 & 1.1645 \\
\hline Transfer efficiency & $\mathrm{M}$ & 0.9013 & -0.3035 & -0.5911 & 0.5124 & -0.2557 & -0.3333 \\
\cline { 2 - 8 } & SD & 0.9922 & 1.1227 & 0.9082 & 0.9184 & 1.2428 & 0.9512 \\
\hline
\end{tabular}

Figure 2 gives a visual presentation of the performance efficiency of the recall and transfer tasks for each EL group. As for the EL factor, a significant main effect of the EL was observed on the performance efficiency of the recall task, $F(2,81)=6.868$, $M S E=1.072, p=0.002, \eta^{2}=0.145$, and on the transfer test scores, $F(2,81)=10.534$, $M S E=1.067, p=0.000, \eta^{2}=0.206$. Post hoc comparisons (LSD) of the different groups for both the recall and transfer tasks revealed that the high EL group had higher performance efficiency than the medium and low EL groups. No interaction was found between the presentation mode and EL on the performance efficiency of either the recall task, $F(2,81)=0.763, M S E=1.072, \mathrm{P}=0.470$, or the transfer task, $F(2,81)=0.726$, $M S E=1.067, p=0.487$. 

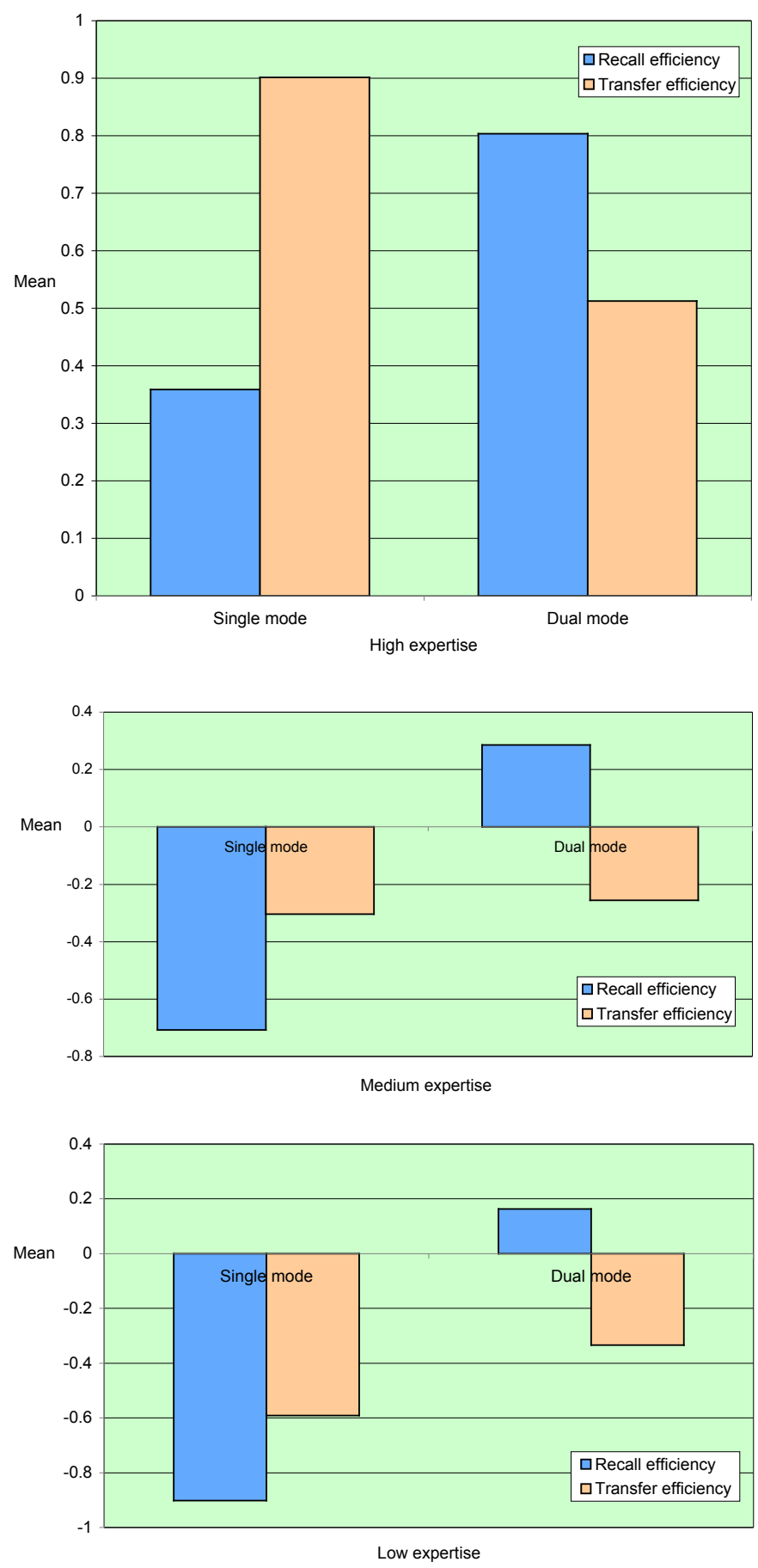

Figure 2: The efficiency of the presentation mode on the recall and transfer tasks for different EL groups, with high (top), medium (middle) and low expertise (bottom) 


\section{Discussion}

The present research extended the previous study of Diao et al. (2007) on the effects of text aids for L2 listening comprehension with mobile devices as the content delivery tool. According to the expertise reversal effect of the CLT, the effectiveness of the content presentation mode depends on the learners' expertise level in the target subject. The modality effect appears when one mode acts as a compensation for the other, whereas the redundancy effect arises when the two modes are redundant and only add to the memory load in the cognitive process. The results of this study were consistent with Diao et al.'s findings, in that the presence of the text contributed to a lower cognitive load as well as enhancing performance in the immediate recall task, but not the subsequent transfer task of L2 listening comprehension. In other words, the previous training session, with or without the aid of written text, did not bring about a significant difference in the skill transfer task. Similar results were found when we examined the effectiveness of the presentation mode from the perspective of performance efficiency. The training with identical text plus spoken message was more efficient for the factual recall task, but not for the transfer task.

Inspection of the performance efficiency of the presentation modes by the EL group indicated that the dual mode was more efficient in the immediate recall task. This was especially evident for the medium and low EL groups. However, the effect did not extend to the skill transfer task. Although no statistical significance was obtained, a reverse effect in the skill transfer task was detected in the high EL group. The redundancy of the presentation mode may result in the reverse effect for the advanced learners, because the redundant information imposes an extra cognitive load rather than facilitating learning.

Based on the results from this study, the following conclusions can be made. First of all, the modality effect applies better to participants with a lower level of linguistic ability in immediate factual recall. The text aid for fact acquisition should ease the concern regarding small screen size. With increasing screen size in the latest models of smart phones and tablet PCs, this will no longer be a critical problem. However, this experiment was only a simulation of mobile learning conducted in a classroom. How text affects cognitive load when students are literally on the move needs further investigation. In addition, training with the dual mode did not extend its effect to the subsequent skill transfer task. In other words, the learners presented with the dual mode did not develop the skill required in the later stage; this means that the written aid did not help the construction of the schema connecting the visual and audio text.

This study has provided important implications for content presentation with mobile devices. If the goal of listening is to obtain information, text aid supplements will facilitate L2 comprehension, especially for the lower-level EL learners. If the purpose of listening is to improve the listening ability of L2, the provision of text aids may not be a good strategy and may even be counter-productive for advanced learners. Instructors should inform their students that while using mobile devices for language learning, their choice of studying with or without text aids should depend on their levels of listening comprehension and learning goals (for factual knowledge or skill development). Moreover, the m-learning model discussed in the current study, compared to desktop-bound activities, presents more extensive possibilities for learning foreign languages. Instead of confining learners to the desktops, the instructors can take advantage of immersive learning environments, such as audio 
guides for places like museums, galleries, exhibition centres, etc, with either mode (dual or single) selectable, for students to interact directly with various learning targets. Finally, through this experiment, the instructor and students experienced the immediate convenience of mobile devices as an economical way of building a digital laboratory. With a PDA in hand, the learners enjoyed everything they used to do with PCs. The results apply to other mobile devices, such as smart phones, iPods, laptops, etc, which can replace each other to serve the same function.

\section{Conclusion}

This study provides users of mobile learning - whether as as instructional material designers, instructors, or learners - guidance on the most effective content presentation modes with these devices. This study concludes that redundancy of audio and visual presentation assists the learners of the present study with lower linguistic ability in gaining factual information; however, it loses its advantage when the learners apply the skill in other contexts, such as the extended passage in this study. The benefits could be reversed with learners having higher linguistic ability, especially in terms of performance efficiency. When the effective content adaptation is concerned, instructors are advised to take instructional objectives, whether it is for obtaining factual knowledge or developing L2 listening skill, into consideration and then incorporate proper strategies accordingly.

\section{References}

Ally, M. (2004). Using learning theories to design instruction for mobile learning devices. In J. Attewell \& C. Savill-Smith (Eds), Mobile learning anytime, anywhere: A book of papers from MLEARN 2004. [viewed 13 Jul 2008]. http:/ / www.mobilearn.org/download/events/ mlearn_2004/MLEARN_\%202004_book_of_conference_papers.pdf

Baddeley, A. D. (2000). The episodic buffer: A new component of working memory? Trends in Cognitive Science, 4(11), 417-423. http: / / dx.doi.org/10.1016/S1364-6613(00)01538-2

Borg, G., Bratfisch, O. \& Dornic, S. (1971). On the problem of perceived psychology. Scandinavian Journal of Psychology, 12, 249-260.

Chase, W. G. \& Simon, H. A. (1973). Perception in chess. Cognitive Psychology, 4(1), 55-81. http: / / dx.doi.org/10.1016/0010-0285(73)90004-2

Chen, C. M. \& Chung, C. J. (2008). Personalized mobile English vocabulary learning system based on item response theory and learning memory cycle. Computers $\mathcal{E}$ Education, 51(2), 624645. http:/ / dx.doi.org/10.1016/j.compedu.2007.06.011

Chen, I. J. \& Chang, C. C. (2011). Content presentation modes in mobile language listening tasks: English proficiency as a moderator. Computer Assisted Language Learning, 24(5), 451-470. http: / / dx.doi.org/10.1080/09588221.2011.577749

Chen, N. S., Hsieh, S. W. \& Kinshuk (2008). Effects of short-term memory and content representation type on mobile language learning. Language Learning E Technology, 12(3), $93-$ 113. http:/ / adapt.athabascau.ca/ publications / papers/1lt_2008.pdf

Cheung, W. S. \& Hew, K. F. (2009). A review of research methodologies used in studies on mobile handheld devices in K-12 and higher education settings. Australasian Journal of Educational Technology, 25(2), 153-183. http:/ / www.ascilite.org.au/ajet/ ajet25/ cheung.html

Chinnery, G. M. (2006). Going to the MALL: Mobile assisted language learning. Language Learning and Technology, 10(1), 9-16. http: / /lt.msu.edu/vol10num1/ emerging/default.html 
Chung, K. K. H. (2008). What effect do mixed sensory mode instructional formats have on both novice and experienced learners of Chinese characters? Learning and Instruction, 18(1), 96-108. http: / / dx.doi.org/10.1016/j.learninstruc.2007.01.001

Cooney, G. \& Keogh, K. A. (2007). Use of mobile phones for language learning and assessment for learning, a pilot project. Paper presented at mLearn 2007, Melbourne. [verified 15 Jan 2012] http:/ / www.learnosity.com/files / learnosity-use-of-mobile-phones-for-languagelearning-and-assessment-for-learning.pdf

Cooper, G. (1998). Research into cognitive load theory and instructional design at UNSW. [viewed 13 Jul 2008, verified 15 Jan 2012] http: / / paedpsych.jku.at:4711/LEHRTEXTE/Cooper98.html

Davis, S. (2003). Observations in classrooms using a network of handheld devices. Journal of Computer Assisted Learning, 19, 298-307. http:/ / dx.doi.org/10.1046/j.0266-4909.2003.00031.x

DeLeeuw, K. E. \& Mayer, R. E. (2008). A comparison of three measures of cognitive load: Evidence for separable measures of intrinsic, extraneous, and germane load. Journal of Educational Psychology, 100(1), 223-234. http: / / dx.doi.org/10.1037/0022-0663.100.1.223

Diao, Y., Chandler, P. \& Sweller, J. (2007). The effect of written text on comprehension of spoken English as a foreign language. American Journal of Psychology, 120(2), 237-261. http: / / www.jstor.org/ stable/ 20445397 [viewed 9 Jan 2012]

Geddes, S. J. (2004). Mobile learning in the 21st century: Benefit for learners. Knowledge Tree ejournal, 30(3), 214-228. [viewed 9 Jan 2012] http: / / knowledgetree.flexiblelearning.net.au / edition06/ download/Geddes.pdf

Goh, C. C. (2000). A cognitive perspective on language learners' listening comprehension problems. System, 28(1), 55-75. http: / / dx.doi.org/10.1016/S0346-251X(99)00060-3

Hsi, S. (2003). A study of user experiences mediated by nomadic web content in a museum. Journal of Computer Assisted Learning, 19(3), 308-319. http: / / dx.doi.org/10.1046/j.02664909.2003.jca_023.x

Hung, H. C. \& Young, S. C. (2007). Constructing the game-based learning environment on handheld devices to facilitate English vocabulary building. Paper presented at the Seventh IEEE International Conference on Advanced Learning Technologies, Niigata, Japan. http: / / dx.doi.org/10.1109/ICALT.2007.105

Jamet, E. \& Bohec, O. L. (2007). The effect of redundant text in multimedia instruction. Contemporary Educational Psychology, 32, 588-598. http: / / dx.doi.org/10.1016/j.cedpsych.2006.07.001

Jones, L. C. \& Plass, J. L. (2002). Supporting listening comprehension and vocabulary acquisition in French with multimedia annotations. The Modern Language Journal, 86(4), 546-561. http: / / dx.doi.org/10.1111/1540-4781.00160

Kalyuga, S., Chandler, P. \& Sweller, J. (1998). Levels of expertise and instructional design. Human Factors, 40, 1-17. http: / / dx.doi.org/10.1518/001872098779480587

Kalyuga, S., Chandler, P. \& Sweller, J. (1999). Managing split-attention and redundancy in multimedia instruction. Applied Cognitive Psychology, 13(4), 351-371. http: / / dx.doi.org/10.1002 / (SICI)1099-0720(199908)13:4<351::AID-ACP589>3.0.CO;2-6

Kalyuga, S., Chandler, P. \& Sweller, J. (2000). Incorporating learner experience into the design of multimedia instruction. Journal of Educational Psychology, 92(1), 126-136. http: / / dx.doi.org/10.1037/0022-0663.92.1.126

Kao, C. C. (2006). EFL listening comprehension strategies used by students at the Southern Taiwan University of Technology. Unpublished doctoral dissertation, University of South Dakota. 
Kukulska-Hulme, A. (2009) Will mobile learning change language learning? ReCALL, 21(2), 157165. http:/ / dx.doi.org/10.1017/S0958344009000202

Kukulska-Hulme, A. \& Traxler, J. (2005). Mobile teaching and learning. In A. Kukulska-Hulme \& J. Traxler (Eds.), Mobile learning: A handbook for educators and trainers (pp.25-44). London: Routledge.

Leahy, W., Chandler, P. \& Sweller, J. (2003). When auditory presentations should and should not be a component of multimedia instruction. Applied Cognitive Psychology, 17, 401-418. http: / / dx.doi.org/10.1002/acp.877

Mayer, R. E., Heiser, J. \& Lonn, S. (2001). Cognitive constraints on multimedia learning: When presenting more material results in less understanding. Journal of Educational Psychology, 93(1), 187-198. http: / / psycnet.apa.org/doi / 10.1037/0022-0663.93.1.187

Mayer, R. E. \& Moreno, R. (1998). A split-attention effect in multimedia learning: Evidence for dual processing systems in working memory. Journal of Educational Psychology, 90(2), 312-320. http: / / psycnet.apa.org/doi/10.1037 / 0022-0663.90.2.312

Moreno, R. \& Mayer, R. E. (2002). Verbal redundancy in multimedia learning: When reading helps listening. Journal of Educational Psychology, 94(1), 156-163. http: / / psycnet.apa.org/doi/10.1037 / 0022-0663.94.1.156

Mousavi, S. Y., Low, R. \& Sweller, J. (1995). Reducing cognitive load by mixing auditory and visual presentation modes. Journal of Educational Psychology, 87(2), 319-334. http: / / psycnet.apa.org/doi / 10.1037 / 0022-0663.87.2.319

Nash, S. S. (2007). Mobile learning, cognitive architecture and the study of literature. Issues in Informing Science and Information Technology (IISIT), 4, 811-818. [viewed 9 Jan 2012] http: / / proceedings.informingscience.org/InSITE2007/IISITv4p811-818Nash399.pdf

Osada, N. (2004). Listening comprehension research: A brief review of the past thirty years. Dialogue, 3, 53-66. http:/ / talk-waseda.net/dialogue/ no03_2004/2004dialogue03_k4.pdf [viewed 9 Jan 2012]

Paas, F. \& Van Merriënboer, J. J. G. (1993). The efficiency of instructional conditions: An approach to combine mental effort and performance measures. Human Factors, 35(4), 737-743. http: / / dx.doi.org/10.1177/001872089303500412

Paas, F. \& Van Merriënboer, J. J. G. (1994). Instructional control of cognitive load in the training of complex cognitive tasks. Educational Psychology Review, 6(4), 351. http: / / dx.doi.org/10.1007/BF02213420

Paas, F., Van Merriënboer, J. J. G. \& Adam, J. J. (1994). Measurement of cognitive load in instructional research. Perceptual and Motor Skills, 79, 419-430. http: / / dx.doi.org/10.2466/pms.1994.79.1.419

Pettit, J. \& Kukulska-Hulme, A. (2007). Going with the grain: Mobile devices in practice. Australasian Journal of Educational Technology, 23(1), 17-33. http: / / www.ascilite.org.au/ajet/ajet23 / pettit.html

Saran, M., Cagiltay, K. \& Seferoglu, G. (2008). Use of mobile phones in language learning: Developing effective instructional materials. Paper presented at the 5th IEEE International Conference on Wireless, Mobile and Ubiquitous Technologies in Education, Beijing, China. http:/ / dx.doi.org/10.1109/WMUTE.2008.49

Stockwell, G. (2007). Vocabulary on the move: Investigating an intelligent mobile phone-based vocabulary tutor. Computer Assisted Language Learning, 20(4), 365-383. http: / / dx.doi.org/10.1080/09588220701745817 
Sweller, J. (1993). Some cognitive processes and their consequences for the organization and presentation of information. Australian Journal of Psychology, 45, 1-8.

http: / / dx.doi.org/10.1080/00049539308259112

Sweller, J. (2003). Evolution of human cognitive architecture. In B. Ross (Ed.), The psychology of learning and motivation (Vol. 43, pp. 215-266). San Diego, CA: Academic Press.

http: / / dx.doi.org/10.1016/S0079-7421(03)01015-6

Sweller, J. (2005). Implications of cognitive load theory for multimedia learning. In R. E. Mayer (Ed.), The Cambridge handbook of multimedia learning (pp.19-29). New York: Cambridge University Press. http: / dx.doi.org/10.1016/S0959-4752(01)00014-7

Van Merriënboer, J. J. G. \& Sweller, J. (2005). Cognitive load theory and complex learning: Recent developments and future directions. Educational Psychology Review, 17(2), 147-177. http: / / dx.doi.org/10.1007/s10648-005-3951-0

Yeung, A. S., Jin, P. \& Sweller, J. (1997). Cognitive load and learner expertise: Split-attention and redundancy effects in reading with explanatory notes. Contemporary Educational Psychology, 23(1), 1-21. http: / / dx.doi.org/10.1006/ceps.1997.0951

\section{Appendix 1: Extract of passages and comprehension questions used in phase 1}

\section{Elephants}

The largest land animals, wild elephants live approximately 70 years. There are two major kinds of elephants living today: the African and the Asian. Even though African and Asian elephants look similar, their physical characteristics differ slightly. One of the elephants' most distinct features is its trunk, a long nose made from the upper lip. Elephants utilize their trunks to grab objects. Asian elephants possess smooth trunks, compared to the rough-skinned trunks of their African relatives....

Listening comprehension question (audio only during the test)

1. How many major kinds of living species of elephants there are at present?
a. Five
b. Four
c. Three
d. Two

\section{Appendix 2: Extract of passage and example of listening comprehension questions used in phase 2}

The words in boldface were repeated in the materials of both phases.

Tennis

Tennis is a sport played between two competitors or two teams of two players each. Originating in the United Kingdom, tennis is approximately 150 years old and now attracts adults and children, male and female alike. Despite its long history, the rules of modern tennis remain similar to the original game.

A tennis match contains three to five sets, which each consist of a series of shorter games. During a game, tennis players score points by utilizing their rackets to launch a ball back and forth across a net. They engage in constant aerobic activity, with short bursts of intense physical power. The goal is to acquire adequate points to win the game....

Listening comprehension question (audio only during the test) 
1. Where is tennis originated?
a. The United States
b. The Great Britain
c. The United Nations
d. United Arab Emirates

Authors: I-Jung Chen, Associate Professor, Department of Applied Foreign Languages, Takming University of Science and Technology

No.56, Sec.1, Huan-shan Rd, Taipei, Taiwan. Email: ijungchen@gmail.com

Chi-Cheng Chang, Professor, Department of Technology Application and Human Resource Development, National Taiwan Normal University

162, He-Ping East Road, Sec. 1, Taipei, Taiwan. Email: samchang@ntnu.edu.tw

Jung-Chuan Yen, Assistant Professor, Department of Multimedia Design, Takming University of Science and Technology

No. 56, Sec.1, Huan-shan Rd, Taipei, Taiwan. Email: lcyan2003@gmail.com

Please cite as: Chen, I. J., Chang, C. C. \& Yen, J. C. (2012). Effects of presentation mode on mobile language learning: A performance efficiency perspective. Australasian Journal of Educational Technology, 28(1), 122-137.

http:/ / www.ascilite.org.au/ajet/ajet28/chen-ij.html 